\title{
Oligosacáridos de la leche humana. Crecimiento y desarrollo
}

\section{Oligosaccharides from human milk. Growth and development.}

La leche humana es considerada como un tejido en forma líquida, compuesto por células vivas y múltiples factores bioquímicos funcionales que aportan, más que ninguna otra fórmula, grandes ventajas al crecimiento y desarrollo del ser humano al inicio de la vida.

El desarrollo tecnológico ha brindado la posibilidad de identificar más componentes y sus respectivas funciones en la leche de las madres que lactan. Leche que se diferencia de la de otros mamíferos por la concentración de sus elementos y por la presencia de algunos factores casi exclusivos de la raza humana; propiedades que el recién nacido sano asimila perfectamente gracias a sus sistemas digestivo, de absorción y metabólicos adaptados biológicamente. ${ }^{1}$

La lactosa es el compuesto más abundante en la leche de los mamíferos; sin embargo, no es el único carbohidrato presente. La identificación de otras moléculas mediante espectrometría de masa por absorción atómica generó la identificación de otros carbohidratos relacionados a la lactosa, pero con otra estructura de mayor complejidad bioquímica que califican como oligosacáridos. Éstos oligosacáridos de la leche humana (HMO por sus siglas en inglés) son carbohidratos identificados el siglo pasado y están relacionados a lo que se ha llamado fibra de la dieta. Son glicanos no conjugados que tienen su mayor concentración en la leche del humano.

En 1926 Khun y György describieron los factores de crecimiento de las Bifidobacterias a las que se les Ilamó originalmente gynolactosa o factor bífido, lo que posteriormente dio lugar al término de oligosacáridos de la leche. Durante muchos años se creyó que la función de los oligosacáridos de la leche humana era la de un prebiótico que estimulaba el desarrollo de una microbiota bífida deseable en el recién nacido y lactante; ahora se sabe que tienen más funciones. 
Estudios en modelos in vitro o en animales han demostrado funciones que previenen las infecciones bacterianas, virales y por protozoarios al actuar como receptores falsos y desviar la posible adherencia de los patógenos a la mucosa intestinal. También se ha encontrado que los oligosacáridos de la leche humana modulan la respuesta inmunológica celular en el epitelio intestinal, disminuyen la infiltración y activación de los leucocitos y, en estudios preclínicos, se propone que participan en la prevención de enterocolitis necrosante y aportan ácido siálico que promueve el desarrollo del cerebro y su capacidad cognitiva. Además se han propuesto como protectores de enfermedades alérgicas dependientes de IgE. ${ }^{2}$

Se han encontrado diferentes patrones de oligosacáridos entre las especies de mamíferos. La leche del ser humano contiene la mayor concentración de éstos entre los mamíferos. Un ejemplo comparativo: la leche humana tiene concentraciones de oligosacáridos que varían entre 5 y $15 \mathrm{~g} / \mathrm{L}$, mientras que la leche de vaca tiene tan solo $0.05 \mathrm{~g} / \mathrm{L}$. También se han observado diferencias significativas al identificar las más de 100 estructuras moleculares de los oligosacáridos de la leche humana (en contraste la leche de vaca tiene solo 40). Además los seres humanos secretan concentraciones y composiciones variables de oligosacáridos. La mayor concentración está dada por aproximadamente 20 estructuras bioquímicas. La 2'-Fucosyl-lactosa (2'-FL) se ha identificado como el oligosacárido más abundante de la leche humana; la fucosilación se ha relacionado con factores como el sistema histocompatible sanguíneo, específicamente el secretor y el de Lewis. Aproximadamente 80\% de las madres lactantes en Europa y América son secretoras de 2'-FL. En México un estudio reveló el $100 \%$ de madres secretoras. ${ }^{3}$

El interés en conocer el espectro funcional de los oligosacáridos de la leche humana natural- mente se dirige al área de la nutrición. ¿Cuál es el papel de estos oligosacáridos no digeribles en el crecimiento y en el desarrollo de un recién nacido y un lactante alimentados con ellos? La evidencia clínica actual es limitada a tres trabajos publicados recientemente, los cuales fueron financiados por la industria.

Marriage y sus colaboradores ${ }^{4}$ realizaron un estudio de intervención para medir tolerancia y crecimiento en lactantes alimentados con tres fórmulas diferentes de manera ciega para los padres, dos de ellas suplementadas con $2^{\prime}$ FL en diferentes concentraciones. La densidad calórica de las tres fórmulas fue de $64.3 \mathrm{kcal} /$ dL. Participaron 38 centros de Estados Unidos de Norteamérica, se incluyeron 338 recién nacidos sanos de término, eutróficos de menos de 5 días de vida a quienes se les siguió durante 4 meses. Se formaron tres grupos de acuerdo con la fórmula administrada.

El contenido total de oligosacáridos fue de $2.4 \mathrm{~g} / \mathrm{L}$ en las tres fórmulas, a dos se les adicionó $2^{\prime}$-FL en diferentes concentraciones, una con $0.2 \mathrm{~g} / \mathrm{L}$ y la otra $1.0 \mathrm{~g} / \mathrm{L}$ en adición a galactooligosacáridos artificiales. La fórmula control fue una fórmula regular con galactooligosacáridos artificiales. También se incluyó un cuarto grupo de recién nacidos alimentados exclusivamente con leche humana directamente del pecho o en botella. El objetivo primario fue estudiar el crecimiento en los primeros 4 meses de vida, y los secundarios la tolerancia digestiva, la absorción y los marcadores sanguíneos de inmunidad.

Los resultados mostraron crecimiento similar de los tres grupos en relación al grupo alimentado con leche humana; la tolerancia de las fórmulas adicionadas con $2^{\prime}$-FL fue buena; la relación entre absorción/excreción de 2'-FL fue dosis dependiente; se encontró una disminución de los niveles sanguíneos y urinarios de 2'-FL entre los lactantes de 42 y los de 119 días de edad, 
hallazgo que correlaciona con las concentraciones decrecientes de 2'-FL en la leche humana a estas edades.

Los autores concluyen que las fórmulas adicionadas con 2'-FL son bien toleradas, que generan crecimientos similares a los lactantes alimentados con leche humana en los primeros 4 meses de edad y que el perfil de absorción/excreción de 2'-FL en las fórmulas es comparable al de la leche humana.

Otro estudio publicado 5 incluyó, de manera prospectiva, aleatorizada, ciega, tres grupos comparables de recién nacidos sanos, de término, en los primeros 8 días de vida. Un grupo recibió fórmula regular sin oligosacáridos, otro recibió fórmula con $2.2 \mathrm{~g} / \mathrm{L}$ de oligosacáridos, de los cuales 2'-FL aportó $0.2 \mathrm{~g} / \mathrm{dL}$ y FOS $2.0 \mathrm{~g} / \mathrm{L}$; el tercer grupo recibió leche humana. El objetivo primario fue evaluar la consistencia de las heces y además se midió crecimiento, nivel de ingestas y la opinión de los padres. Los resultados fueron similares en los tres grupos para consistencia de las heces, ingestas, medidas antropométricas y frecuencia de regurgitaciones. La frecuencia de evacuaciones por día resultó significativamente mayor en el grupo alimentado con leche humana en comparación con los dos grupos con fórmula. Los autores concluyen que la fórmula que contiene $2^{\prime}$-FL fue bien tolerada y ofreció crecimiento comparable a la leche humana.

Otro estudio en dos centros europeos, aleatorizado, doble ciego, de publicación reciente, ${ }^{6}$ exploró una fórmula que contiene 2'-FL y lacto$\mathrm{N}$-neotetraosa, oligosacárido no fucosilado presente también en la leche humana; evaluó el crecimiento de lactantes durante 6 meses, las medidas antropométricas, la tolerancia, la morbilidad durante el seguimiento y la necesidad de medicamentos como antibióticos. Se comparó con una fórmula idéntica excepto por el contenido de oligosacáridos de la leche humana.
Se incluyó a 175 recién nacidos y se encontró que no hubo diferencias entre los grupos en los parámetros de crecimiento durante los primeros 4 meses de alimentación exclusiva con fórmula, durante la introducción de alimentos complementarios y después de haber descontinuado la fórmula con oligosacáridos de leche humana hasta el año de edad. El reporte de los padres indicó menor incidencia de bronquitis y menor uso de antibióticos en los lactantes que recibieron la fórmula suplementada con oligosacáridos de la leche humana.

La suplementación de las fórmulas con 2'-FL y con 2'-FL y LNnT de acuerdo con la evidencia accesible y limitada no ocasiona efectos adversos en los recién nacidos tratados con diferentes esquemas y concentraciones. El crecimiento es similar a los lactantes alimentados con leche humana y con otras fórmulas no suplementadas. Al parecer los oligosacáridos de la leche humana también generan un efecto positivo en disminuir la morbilidad y la necesidad de medicamentos como antibióticos. El argumento de conflicto sobre la presencia de intereses de los laboratorios en la ejecución de estos estudios es válido; sin embargo, analizar la metodología y el tratamiento estadístico, así como la consistencia de los resultados entre los tres estudios de diferentes firmas comerciales ofrece confianza en la credibilidad de los resultados. Necesitamos extrapolar estos diseños a países con diferente genética y cultura como la nuestra para confirmar el potencial de los oligosacáridos de la leche humana en la dieta del recién nacido y del lactante menor.

\section{REFERENCIAS}

1. Abrahams SW, Labbok MH. Breastfeeding and otitis media: A review of recent evidence. Curr Allergy Asthma Rep. 2011;11:508-512.

2. Bode L. Human milk oligosaccharides: Every baby needs a sugar mama. Glycobiology. 2012;22:1147-1162.

3. Castanys-Muñoz E, Martin MJ, Prieto PA. 2'fucosyllactose: an abundant, genetically determined soluble glycan present in human milk. Nutrition Reviews. 2016;71;773-789. 
4. Marriage BJ, Buck RH, Ghoering KC, Oliver JS, Williams JA. Infant fed a lower calorie formula of 2FL show growth and 2'FL uptake like breast fed infants. JPGN. 2015;61:649-658.

5. Kajser. Gastrointestinal tolerance of formula supplemented with oligosaccharides. Faseb J. 2016;30:suppl 671.4

6. Puccio G, Alliet P, Cajozzo C, Janssens E, Corsello G, Sprenger N, Wernimont S, Egli D, Gosoniu L, Steenhout P. Effects of infant formula with human oligosaccharides on growth and morbidity: a randomized multicenter trial. JPGN 2017;64:624-31.

\section{Dr. José Armando Madrazo de la Garza}

Pediatra y Gastroenterólogo

Hospital Ángeles de las Lomas

Presidente de la Sociedad Latinoamericana de

Gastroenterología, Hepatología

y Nutrición Pediátrica (LASPGHAN)

jarmando.madrazo@gmail.com 